\title{
Development of the Zebrafish Enteric Nervous System
}

\author{
lain Shepherd ${ }^{1}$ and Judith Eisen ${ }^{2}$ \\ lain Shepherd: ishephe@emory.edu; Judith Eisen: eisen@uoneuro.uoregon.edu \\ ${ }^{1}$ Department of Biology, Emory University, Rollins Research Building, 1510 Clifton Road, Atlanta \\ GA 30322, tel: 404-727-6292, fax: 404-727-2880 \\ ${ }^{2}$ Institute of Neuroscience, 1254 University of Oregon, Eugene OR 97403, tel: 541-346-4524, fax: \\ 541-346-4548
}

\begin{abstract}
The enteric nervous system is composed of neurons and glia that modulate many aspects of intestinal function. The ability to use both forward and reverse genetic approaches and to visualize development in living embryos and larvae has made zebrafish an attractive model in which to study mechanisms underlying enteric nervous system development. Here we review recent work describing the development and organization of the zebrafish enteric nervous system and how this relates to intestinal motility. We also discuss the cellular, molecular and genetic mechanisms that have been revealed by these studies and how they are providing new insights into human enteric nervous system diseases.
\end{abstract}

\section{Introduction}

The enteric nervous system (ENS) is composed of neurons and glia that provide intrinsic innervation to the intestinal tract and modulate functions such as motility, homeostasis and secretion (Burns and Pachnis, 2009; Furness, 2006). The ENS is the largest division of the peripheral nervous system (PNS) and is the only division able to function independent of innervation from the central nervous system (CNS) (Furness, 2006). Considering that over 40 percent of patients who visit medical practioners do so because they have intestinal malfunctions (Gershon, 1998), learning how the ENS develops and functions is crucial for understanding human health and disease, as well for understanding basic mechanisms of neural development.

The ENS is derived entirely from the neural crest (Le Douarin and Kalcheim, 1999). Studies from many species have led to an understanding of the basic mechanisms of neural crest formation (Sauka-Spengler and Bronner-Fraser, 2008), although it remains unclear when enteric neural crest becomes specified. Many signaling pathways, including the BMP, FGF, WNT and Notch signaling pathways are required for induction of neural crest and specification of distinct subtypes of neural crest derivatives (Sauka-Spengler and BronnerFraser, 2008). However, what specifies and guides ENS precursors to the intestinal tract is still unknown. Defined roles though have been established for specific signaling pathways necessary for migration, proliferation and differentiation of enteric neural crest precursors after these cells have reached the gut. These signaling pathways include the GDNF, Endothelin, BMP, Hedgehog, Retinoic Acid, Notch, Semaphorin and Netrin pathways [reviewed in (Burzynski et al., 2009)]. 
Several transcription factors have also been implicated in ENS development including Mash1, Pax3, Phox2b, Hand2, Hox11a and Hoxb5 [reviewed in (Burzynski et al., 2009)]. Although considerable work has been carried out on ENS development, there are still many outstanding questions that remain unresolved. For example, we still do not have a good understanding of how the lineages of specific types of enteric neurons are specified, how enteric circuitry is established, or the extent of ENS abnormalities that may result in human intestinal disorders (Gershon, 2010).

The ability to use both forward and reverse genetic approaches and to visualize development in living embryos and larvae has made zebrafish an excellent model in which to study mechanisms underlying ENS development and to gain insights into diseases affecting the human ENS (Burzynski et al., 2009). Here we review studies using zebrafish that have provided a new understanding of the cellular, molecular and genetic mechanisms underlying ENS development and the establishment of intestinal motility. Many of these studies are also providing new insights into human digestive tract diseases.

\section{Organization of the zebrafish intestinal tract}

The intestinal tract, often referred to as the gut, is a complex organ comprised of several different cell types, including the gut epithelium, gut musculature, vasculature, immune cells and the ENS. The teleost gut is generally similar to that of mammals, although it is somewhat simpler in overall architecture (Wallace et al., 2005) (see Figure 1). For example, in zebrafish the esophagus connects directly to the intestine without the presence of a stomach (Wallace et al., 2005). The beginning of the intestine is defined by the insertion of the common hepatic-pancreatic duct and by digestive enzymes characteristic of the intestine (Wallace and Pack, 2003). Even though there is no stomach, the anterior embryonic intestine is enlarged and may function as a food reservoir. This anterior intestinal region, known as the intestinal bulb, also has retrograde motility that differs from the predominantly anterograde propulsive motility observed in the posterior intestine (Holmberg et al., 2007). The intestinal bulb also contains a few scattered goblet cells that produce both acid and neutral mucins (Ng et al., 2005). Furthermore, the patterns of sox2, barx1, gata5 and gata6 expression in the anterior zebrafish intestine resemble those of the developing mammalian stomach (Muncan et al., 2007) and may allow this section of the gut to develop additional functions of storage and mixing of luminal contents. In addition to lacking a stomach, the structure of the zebrafish gut epithelium is simpler than that of amniotes. The zebrafish gut epithelium lacks crypts and is arranged in broad, irregular folds rather than forming villi ( $\mathrm{Ng}$ et al., 2005; Wallace et al., 2005). Zebrafish also lack a submucosa layer found in the guts of amniotes (Wallace et al., 2005) that contains a large amount of connective tissue and large blood vessels and lymphatics. The vascular tissue in the zebrafish intestine is found in the mucosa and the muscularis.

In addition to host cells, the vertebrate gut is home to a vast consortium of microbial cells typically referred to as the gut microbiota (Cheesman and Guillemin, 2006; Kanther and Rawls, 2010). The collective genome of the gut microbiota exceeds that of the host by several orders of magnitude and encodes critical digestive capacities absent from the host genome (Gill et al., 2006), suggesting a crucial role for this co-evolved community in intestinal development and function. The role of the microbiota in gut development has been investigated by rearing animals in a sterile environment and comparing them with conventionally-reared animals. The importance of the microbiota in gut development has been revealed by studies in both mouse and zebrafish showing that in the absence of gut microbiota, programs of gut epithelial cell type specification and maturation are altered (Backhed et al., 2005; Bates et al., 2006). Interestingly, one aspect of zebrafish gut function that is affected by absence of the microbiota is motility (Bates et al., 2006), raising the 
possibility that the gut microbiota influence development of the ENS, although this has not yet been tested.

\section{Early development of the ENS}

The zebrafish ENS, like that of all other vertebrates, is derived from the neural crest (Kelsh and Eisen, 2000). In amniote vertebrates, both vagal and sacral neural crest contribute to the ENS (Furness, 2006). In contrast, lineage studies in zebrafish suggest that the entire ENS is derived from vagal neural crest (Shepherd, unpublished data). Consistent with the simpler structure of the zebrafish gut compared with amniotes, migration of neural crest cells along the zebrafish gut also appears simpler than in amniotes. For example, in amniotes neural crest-derived ENS precursors migrate caudally along the developing gut in multiple chains that follow complex and unpredictable trajectories (Druckenbrod and Epstein, 2005; Young et al., 2004). In zebrafish, neural crest-derived ENS precursors migrate from the vagal region to the anterior end of the gut primordium, associate with it, and then migrate as two parallel chains of cells along the length of the developing gut (Figure 2) (Elworthy et al., 2005; Olden et al., 2008; Shepherd et al., 2004). Subsequently ENS precursors migrate circumferentially around the gut and differentiate into enteric neurons and glia. The final organization of the zebrafish ENS is also simpler than that of amniotes, which have two distinct layers of enteric ganglia, the submucosal and the myenteric (Figure 1). Zebrafish lack submucosal ganglia and myenteric neurons are typically arranged as single neurons or neurons pairs (Wallace et al., 2005). How the pattern of ENS precursor migration is determined is currently unknown although recent studies in avians and zebrafish suggest that vascular endothelial cells may be involved in this process (Nagy et al., 2009).

\section{Genetic approaches to studying ENS development}

Unbiased forward mutant screens provide an important methodology for identifying genes involved in a process of interest (Grunwald and Eisen, 2002). Several such screens have now revealed many genes involved in zebrafish ENS development. colourless, one of the first ENS mutants to be isolated, results from a lesion in the sox10 gene (Dutton et al., 2001; Kelsh and Eisen, 2000) which was already known to be important in ENS development in mammals (Southard Smith et al., 1998). Zebrafish screens have also identified other mutations in genes not previously associated with ENS development (Chen et al., 1996; Schilling et al., 1996), for example, the DNA polymerase delta 1 mutant flathead (pold1), the elys nucleopore assembly protein mutant flotte lotte (ahctfi) and the rpc2, RNA polymerase III subunit mutant slim jim (polr3b) (Davuluri et al., 2008; de Jong-Curtain et al., 2008; Plaster et al., 2006; Wallace et al., 2005; Yee et al., 2007). All of these mutants have pleiotropic phenotypes and thus they were not identified based on ENS defects. Nonethe-less, these studies contribute to our knowledge about gut development and offer the potential to help dissect the genetic basis of human intestinal disorders.

Two screens have specifically focused on identifying mutations affecting the ENS (Kuhlman and Eisen, 2007; Pietsch et al., 2006). In both cases, mutants were identified by a change in the number or distribution of enteric neurons as revealed by labeling with an antibody to Elavl3 (previously known as $\mathrm{HuC} / \mathrm{D}$ ), a pan-neuronal protein expressed in differentiated neurons. The screen conducted by Pietsch and colleagues isolated 6 mutations and the screen conducted by Kuhlman and Eisen isolated 13 mutations. The majority of mutants isolated in both screens (15 of 19 mutants) have pleiotropic phenotypes, however, Kuhlman and Eisen identified 4 mutants that appear to affect the ENS specifically. The majority of mutants isolated in both screens (16 of 19 mutants) have a decrease in the number of enteric neurons along the entire length of the intestine, however, Kuhlman and Eisen identified 3 mutants in which enteric neurons are restricted to the anterior region of the gut. Identifying 
the genes that underlie these mutant phenotypes should provide important new insights into the molecular mechanisms involved in ENS development.

The genes responsible for two of the mutations identified in the screen conducted by Pietsch and colleagues have now been determined. One of the mutations is an allele of the previously identified DNA polymerase delta 1 mutant flathead (Plaster et al., 2006). The other mutant, lessen, is a null mutation in the med24 (previously known as trap100) gene (Pietsch et al., 2006). Med24 is a component of the mediator co-transcriptional activation complex previously shown to have an essential role in mouse embryogenesis (Ito et al., 2002). The med 24 null mutant mouse has a placental defect that causes early embryonic lethality, thus no ENS phenotype has been reported. The zebrafish med24 mutant ENS phenotype results from a defect in ENS precursor proliferation after these cells reach the intestine. Surprisingly, Med24 is not expressed in ENS precursors but instead is expressed in the intestinal endoderm. Genetic chimera analysis revealed that wild-type endoderm could rescue the mutant phenotype when transplanted into med 24 mutants, suggesting that an endoderm-derived or endoderm-regulated factor has an altered expression in med24 mutants, and that the change in expression of this factor is responsible for the ENS phenotype (Pietsch et al., 2006).

\section{Molecular mechanisms of ENS development}

Despite developmental and architectural differences between the enteric nervous systems of zebrafish and amniote vertebrates, most of the molecular mechanisms underlying ENS development are conserved among species. For example, signaling through the RET receptor tyrosine kinase is critical for ENS development in both amniotes and zebrafish. ret mRNA is expressed in ENS precursors and differentiating neurons in the developing zebrafish gut (Bisgrove et al., 1997; Marcos-Gutierrez et al., 1997; Shepherd et al., 2004). As in other vertebrate species, zebrafish have two ret isoforms (ret9 and ret51), of which ret51 is unnecessary for complete colonization of the gut by ENS precursors (Heanue and Pachnis, 2008). RET acts together with GFRa, a member of the family of GPI-anchored cell surface receptors, to form a receptor complex that mediates signals of the GDNF neurotrophic factor family (Airaksinen and Saarma, 2002). The role Gfra in development of the zebrafish ENS was tested using morpholino antisense oligonucleotides to create morphants lacking one or more Gfra orthologs. Morpholino-mediated knockdown of the two orthologs of Gfra 1 results in complete loss of ENS neurons and their precursors (Shepherd et al., 2004). However, morpholino-mediated knockdown of Gfra 2 has no apparent effect on ENS development, at least through the first few days of development (Shepherd, unpublished data). Whether this gene functions later in ENS development has not been addressed. Similar to knockdown of RET and Gfra 1, knockdown of GDNF also results in complete loss of zebrafish ENS neurons and their precursors (Shepherd et al., 2001). Two other GDNF family members, Neurturin and Artemin, are reported to be present in zebrafish by immunoreactivity, although whether they function in zebrafish ENS development is unknown (Lucini et al., 2005; Lucini et al., 2004). Interestingly, the Endothelin signaling pathway, which interacts with the RET signaling pathway during development of the ENS in mammals and avians (Landman et al., 2007), may not be required for zebrafish ENS development, because a mutation that perturbs the function of the Endothelin receptor, Ednrb1, does not result in an ENS phenotype in zebrafish (Parichy et al., 2000).

In addition to RET signaling, the function of several transcription factors identified in mouse and avian as potential regulators of Ret expression has also been tested in zebrafish ENS development (Burzynski et al., 2009). Mutants lacking Sox10 (Dutton et al., 2001; Kelsh and Eisen, 2000) or Foxd3 (Montero-Balaguer et al., 2006; Stewart et al., 2006) lack an 
ENS, as do zebrafish in which Phox2b (Elworthy et al., 2005) or Pax3 (Minchin and Hughes, 2008) have been knocked down with morpholino antisense oligonucleotides. In addition to characterizing animals in which genes have been mutated or transiently knocked down, the regulatory regions of the ret, phox $2 b$ and sox 10 genes have been analyzed (Antonellis et al., 2008; Dutton et al., 2008; Fisher et al., 2006; McGaughey et al., 2008).

\section{ENS differentiation}

There are many different types of enteric neurons, including motor neurons, interneurons and intrinsic primary afferent (sensory) neurons. Each of these classes can be further subdivided based on neuronal morphology, physiology and biochemistry. Extensive immunohistochemical analysis in amniotes has revealed that each ENS neuron expresses several different neurotransmitters, and the chemical coding hypothesis posits that the combinatorial expression of these neurotransmitters can be used to functionally define each neuronal class (Furness, 2006). Studies from a number of different laboratories indicate that, similar to amniotes, both excitatory and inhibitory neurotransmitters are expressed by neurons in the zebrafish ENS. Thus, enteric neurons expressing adenylate cyclase-activating polypeptide (PACAP), vasoactive intestinal polypeptide (VIP), calcitonin gene-related polypeptide (CGRP), nitric oxide (NO) neurokinin-A (NKA), substance P, acetylcholine and serotonin have all been reported (Holmberg et al., 2006; Holmberg et al., 2004; Holmberg, 2003; Kuhlman and Eisen, 2007; Olden et al., 2008; Olsson et al., 2008; Pietsch et al., 2006; Poon et al., 2003). Knowledge of the precise chemical coding of the embryonic, larval and adult zebrafish ENS does not currently exist, nor is there a detailed description of the morphologies of the different types of zebrafish enteric neurons. However, a recent study has significantly advanced our understanding of chemical coding in the zebrafish ENS by carefully detailing the proportions of neurons expressing specific neurotransmitters, neurotransmitter synthetic enzymes and downstream signaling components and how these proportions change over time (Uyttebroek et al., 2010). In addition, this study examined coexpression of several different neurotransmitters, neurotransmitter synthetic enzymes and downstream signaling components (Figure 3 ) including, VIP, PACAP, neuronal nitric oxide synthase (nNOS), choline acetyltransferase (ChAT), calbindin (CB), calretinin (CR) and serotonin (Uyttebroek et al., 2010). The distribution and timing of the appearance of these markers in the developing zebrafish ENS is comparable to that seen in amniotes. This information, combined with a detailed analysis of neuronal morphology, will shed considerable light on ENS circuitry in the zebrafish.

\section{Regulation of gut motility}

Intestinal motility arises from coordinated activity of three different cell populations, the ENS, interstitial cells of Cajal (ICC) and gut smooth muscle (Furness, 2006; Rich et al., 2007). The ability to image motility directly in living zebrafish larvae (Holmberg et al., 2007; Holmberg et al., 2006; Holmberg et al., 2004; Holmberg, 2003; Kuhlman and Eisen, 2007) has revealed the complexity of gut motility patterns in vivo. The first spontaneous contractions appear in the zebrafish gut at about 3.5 days postfertilization (dpf) (Kuhlman and Eisen, 2007), well before the onset of feeding at 5-6 dpf (Olsson et al., 2008). The earliest contractions are focal, but contractions begin to propagate along the intestine by 4 dpf and the regularity of contractions increases over the next several days (Holmberg et al., 2007; Holmberg et al., 2006; Kuhlman and Eisen, 2007). Before larvae begin to feed, regular anterograde and retrograde contractions spread from a common point in the middle intestine. Retrograde contractions in the anterior intestine may mix food, as a compensation for the absence of a stomach whereas posterior contractions appear to be primarily propulsive. The posterior most portion of the gut also propagates short contraction waves in both directions (Holmberg et al., 2004). 
ENS cells expressing neuronal markers are first detected at approximately $2 \mathrm{dpf}$ in the zebrafish intestine (Holmberg et al., 2006; Holmberg, 2003; Kelsh and Eisen, 2000), which is prior to the onset of gut motility. The number of enteric neurons increases rapidly over the next three days, a time during which gut smooth muscle is also differentiating (Holmberg, 2003; Olden et al., 2008; Olsson et al., 2008; Seiler et al.; Wallace et al., 2005). Elegant work from the Holmberg lab has shown that although excitatory cholinergic tonus and inhibitory nitergic tonus are present in the zebrafish gut from the onset of feeding (Holmberg et al., 2006; Holmberg et al., 2004), the spontaneous gut contractions seen at 4 dpf are not initiated by intrinsic or extrinsic neuronal innervation (Holmberg et al., 2007). Instead, the ENS has been suggested to have an increasingly important role in modulating intestinal activity late in development, after the onset of feeding behavior (Holmberg et al., 2007). Consistent with this idea, recent work from the Pack lab provides evidence for zebrafish intestinal motility in the absence of innervation (Davuluri et al., 2010). Motility of the zebrafish gut in the absence of ENS function parallels the situation in mouse (Anderson et al., 2004; Ward et al., 1999) and human (Huizinga et al., 2001) in which gut motility can develop in the absence of the ENS. In fact, recent studies in mouse also reveal that the earliest gut contractions are not mediated by the ENS (Roberts et al., 2010). Despite this, and consistent with the idea that the ENS modulates intestinal activity, the regularity of gut contractions in zebrafish appears to roughly correlate with the number of neurons in gutwrencher mutants. These mutants have a decreased number of ENS neurons along the entire length of the intestine and there is an associated decrease in the regularity of gut contractions (Kuhlman and Eisen, 2007) (Figure 4). However, whether ICCs or gut smooth muscle are also affected in this mutant has not been determined.

The initiation of spontaneous gut contractions in zebrafish could be mediated by ICCs. ICCs prominently express the Kit receptor tyrosine kinase and are mesodermal in origin (Lecoin et al., 1996), being derived from the same precursors as intestinal smooth muscle cells (Young, 1999). ICCs generate pacing signals that drive contraction of gut smooth muscle and coordinate neuronal input (Furness, 2006). This cell type is present in zebrafish, although ICCs have not been detected at stages prior to $7 \mathrm{dpf}$ using Kit antibody staining (Rich et al., 2007), thus it is currently unknown precisely when these cells develop in zebrafish. However, like the ENS, ICCs are dispensible for the earliest gut motility in mouse, thus Young and her colleagues suggest that the earliest gut contractions are likely to be myogenic (Roberts et al., 2010). Neither ICC activity nor myogenic activity of the gut musculature have been studied in zebrafish, leaving open the question of the origin of the earliest contractions. A more complete analysis of ENS function will require developing techniques to record electrophysiologically from ENS neurons, ICC cells and intestinal muscles.

\section{Zebrafish ENS as a model for understanding human diseases}

Functional disorders of the human intestine have an enormous impact on the quality of life and extract a high societal cost (Gershon, 2010). Most prevalent among these and the focus of most research is Hirschsprung's disease (HSCR), the major human congenital disorder affecting the intestinal tract (Burzynski et al., 2009; Gershon, 2010). HSCR pathology is characterized by absence of enteric ganglia in a distal segment of the gut, resulting in tonic contraction of the aganglionic segment and intestinal obstruction. Only about 30\% of HSCR cases are familial, whereas about $70 \%$ of HSCR cases occur as an isolated trait. In the majority of families exhibiting such nonsyndromic HSCR, disease transmission displays complex inheritance patterns, thus non-syndromic HSCR is assumed to be a multifactorial disorder (Amiel et al., 2008; Badner et al., 1990). Studies from a number of different groups have shown that mutations in the RET coding sequence account for about $50 \%$ of familial and 15-20\% of sporadic cases of HSCR (Burzynski et al., 2009). Mutational analysis shows 
that genes that interact with RET, such as sox 10 , gdnf and phox $2 b$, are also HSCR loci. Thus, studies of these genes in zebrafish, as well as new genes identified in mutant screens, should provide important insights into the mechanisms underlying this devastating human disease.

HSCR is also manifested as one phenotype of other diseases. For example, patients with Mowat-Wilson syndrome exhibit HSCR as well as craniofacial dysmorphology and other defects. Mutations in the gene encoding the Sip1 transcription factor are implicated in Mowat-Wilson syndrome in humans. Recent work has shown that morpholino-mediated knock down of the two zebrafish orthologs of human SIP1 results in loss of enteric precursors in the intestine and a HSCR-like phenotype (Delalande et al., 2008), paving the way for future studies that will shed more light on the mechanisms underlying this disease.

HSCR is also part of the clinical phenotype of Goldberg-Shprintzen Syndrome (GOSHS) another rare genetic disorder that is characterized by central and enteric nervous system defects and craniofacial abnormalities. This syndrome is caused by null mutations in Kif1binding protein (KBP; also known as KIAA1279) a protein whose precise biological function is unknown (Brooks et al., 2006). Surprisingly, a zebrafish $k b p$ null mutant does not exhibit any of the clinical phenotypes associated with the disease condition (Lyons et al., 2008). However a recent study revealed that KBP interacts with the stathmin-like protein SCG10 both in a yeast two hybrid assay and in vivo. The yeast two hybrid study used mouse KBP to screen a mouse cDNA library; subsequently the interaction between KBP and SCG10 was confirmed by immunoprecipitation. To determine whether $k b p$ and $s c g 10$ interact genetically, an epistasis experiment was undertaken in zebrafish. This experiment revealed an interaction between these two genes by morpholino-mediated knockdown (Alves et al., 2010); aspects of the double morphant phenotype are similar to the GOSHS clinical phenotype. This study in zebrafish provides new insights into the cellular mechanisms underlying GOSHS by suggesting that the central and enteric nervous system phenotypes of this disease result from disruption of the normal microtubule dynamics in neurons requiring SCG10.

In addition to enhancing our understanding of the known HSCR related genes, recent studies in zebrafish have provided novel insights into another disease, Bardet-Biedl syndrome (BBS). BBS is a pleiotropic syndrome that combines facial dysmorphogenesis and HSCR. Perturbing the function of zebrafish $b b s \&$, one of the genes associated with this syndrome, results in craniofacial and ENS defects that mirror those in human patients and mouse models and result from aberrant migration of cranial neural crest cells (Tobin et al., 2008). Because noncanonical Wnt signaling is known to regulate cranial neural crest migration (De Calisto et al., 2005), the authors of this study knocked down Wnt signaling in zebrafish and found a neural crest migration defect similar to that seen in $b b s 8$ morphants (Tobin et al., 2008). They also tested the potential involvement of Hedgehog (Hh) signaling which is known to be important for patterning neural crest cells during craniofacial development (Tapadia et al., 2005). They found that Hh signaling was perturbed and they were able to place Bbs8 within the Hh signaling pathway (Tobin et al., 2008). In independent studies, $\mathrm{Hh}$ signaling was also shown to be essential for ENS development by acting as a potent mitogen for zebrafish ENS precursors (Reichenbach et al., 2008) and to control neural crest cell proliferation and differentiation by modulating responsiveness of cultured mouse neural crest cells to GDNF (Fu et al., 2004). Together these studies provide important new insights into BBS by revealing a potential link between the HSCR phenotype of BBS patients, Hh signaling and RET signaling. 


\section{Future prospects}

ENS development is a complex process involving specification, proliferation, migration, survival and differentiation of neural crest cells and their derivatives, which must finally form circuitry that regulates motility and other intestinal functions. Studies in a variety of models, including mammals, avians and zebrafish have provided an excellent base of knowledge for understanding these processes, however, many of the cellular and molecular mechanisms are as yet unresolved. The conservation of mechanisms across species, coupled with the ability to perform both forward and reverse genetic screens, to follow development of individual cells or cell populations in living embryos and larvae and to characterize intestinal motility in living animals have made zebrafish an attractive model in which to study basic mechanisms of ENS development. These studies will certainly be enhanced by learning more about zebrafish ENS circuitry.

Although HSCR has been the primary focus of research on human ENS-related disorders, there are likely to be other, as yet unrecognized disorders that cause abnormal ENS development and result in abnormal ENS function (Gershon, 2010). At least some of these disorders may arise late in development as a result of failure to elaborate the appropriate lineages of enteric neurons or glia (Gershon, 2010). The experimental tractability of zebrafish, including the ability to follow cell lineages in real time in living embryos and larvae has the potential to reveal cellular and genetic interactions involved in these later processes.

As well as providing new information about the molecular underpinnings of diseases affecting the human ENS, zebrafish may be useful to study physiological processes in real time. For example, a recently-devised screen for intestinal motility based on ingestion and clearing of fluorescent food (Field et al., 2008) should enhance the ability to identify and characterize genes affecting gut motility. Learning to record electrophysiologically from zebrafish ENS neurons in living embryos and larvae will also provide a clear advance to understanding the mechanisms by which the ENS regulates intestinal function, and will provide an important new methodology for characterizing ENS mutants. Motility and other aspects of ENS and gut function are regulated by the neurotransmitter, serotonin. In addition to being present in some ENS neurons, serotonin is produced by enterochromaffin cells in the gut epithelium and drugs that alter 5HT-4 and 5HT-3 serotonin receptors have become major therapeutic agents for a variety of intestinal tract malfunctions, including irritable bowel syndrome (IBS) (Gershon and Tack, 2007). A recent study using differential pulse voltammetry with implantable carbon-fiber microelectrodes to monitor changes in serotonin levels in the zebrafish intestine in vivo (Njagi et al., 2010) opens the door to studying serotonin actions in relation to location and numbers of particular receptors in specific intestinal regions of living animals. Finally, intestinal diseases, such as irritable bowel syndrome and inflammatory bowel disease alter gut motility and can also affect enteric neuron function (Furness, 2006; Lomax et al., 2005). These diseases may result from dysregulation of the intestinal microbiota (Baker et al., 2009; Cheesman and Guillemin, 2006; Furness, 2006; Salonen et al., 2010), thus it is crucial to understand how the microbiota influence ENS function, and whether they also play a role in the later aspects of normal ENS development or homeostasis.

\section{Acknowledgments}

Thanks to Robert Kelsh, Dave Raible and Ken Wallace for critical reading of manuscript drafts. We thank our many colleagues for discussions of ENS development and apologize to any of them whose work was inadvertantly left out of this review. Our original research on the ENS is supported by NIH HD22486 (JE) and DK067285 (IS). 


\section{References}

Airaksinen MS, Saarma M. The GDNF family: signalling, biological functions and therapeutic value. Nat Rev Neurosci. 2002; 3:383-94. [PubMed: 11988777]

Alves MM, Burzynski G, Delalande JM, Osinga J, van der Goot A, Dolga A, de Graaff A, Brooks AS, Metzger M, Eissel U, Shepherd IT, Eggen BJL, Hofstra RMW. KBP interacts with SCG10 linking Goldberg-Shprintzen syndrome to microtubule dynamics and neuronal differentiation. Hum Mol Genet. 2010; 19:3642-51. [PubMed: 20621975]

Amiel J, Sproat-Emison E, Garcia-Barcelo M, Lantieri F, Burzynski G, Borrego S, Pelet A, Arnold S, Miao X, Griseri P, Brooks AS, Antinolo G, de Pontual L, Clement-Ziza M, Munnich A, Kashuk C, West K, Wong KK, Lyonnet S, Chakravarti A, Tam PK, Ceccherini I, Hofstra RM, Fernandez R. Hirschsprung disease, associated syndromes and genetics: a review. J Med Genet. 2008; 45:1-14. [PubMed: 17965226]

Anderson RB, Enomoto H, Bornstein JC, Young HM. The enteric nervous system is not essential for the propulsion of gut contents in fetal mice. Gut. 2004; 53:1546-7. [PubMed: 15361513]

Antonellis A, Huynh JL, Lee-Lin SQ, Vinton RM, Renaud G, Loftus SK, Elliot G, Wolfsberg TG, Green ED, McCallion AS, Pavan WJ. Identification of neural crest and glial enhancers at the mouse Sox10 locus through transgenesis in zebrafish. PLoS Genet. 2008; 4:e1000174. [PubMed: 18773071]

Backhed F, Ley RE, Sonnenburg JL, Peterson DA, Gordon JI. Host-bacterial mutualism in the human intestine. Science. 2005; 307:1915-20. [PubMed: 15790844]

Badner JA, Sieber WK, Garver KL, Chakravarti A. A genetic study of Hirschsprung disease. Am J Hum Genet. 1990; 46:568-80. [PubMed: 2309705]

Baker PI, Love DR, Ferguson LR. Role of gut microbiota in Crohn's disease. Expert Rev Gastroenterol Hepatol. 2009; 3:535-46. [PubMed: 19817674]

Bates JM, Mittge E, Kuhlman J, Baden KN, Cheesman SE, Guillemin K. Distinct signals from the microbiota promote different aspects of zebrafish gut differentiation. Dev Biol. 2006; 297:374-86. [PubMed: 16781702]

Bisgrove BW, Raible DW, Walter V, Eisen JS, Grunwald DJ. Expression of c-ret in the zebrafish embryo: potential roles in motoneuronal development. J Neurobiol. 1997; 33:749-68. [PubMed: 9369149]

Brooks AS, Leegwater PA, Burzynski GM, Willems PJ, de Graaf B, van Langen I, Heutink P, Oostra BA, Hofstra RM, Bertoli-Avella AM. A novel susceptibility locus for Hirschsprung's disease maps to 4q31.3-q32.3. J Med Genet. 2006; 43:e35. [PubMed: 16816022]

Burns AJ, Pachnis V. Development of the enteric nervous system: bringing together cells, signals and genes. Neurogastroenterol Motil. 2009; 21:100-2. [PubMed: 19215587]

Burzynski G, Shepherd IT, Enomoto H. Genetic model system studies of the development of the enteric nervous system, gut motility and Hirschsprung's disease. Neurogastroenterol Motil. 2009; 21:113-27. [PubMed: 19215589]

Cheesman, SE.; Guillemin, K. We know you are in there: conversing with the indigenous gut microbiota. 2006. submitted

Chen JN, Haffter P, Odenthal J, Vogelsang E, Brand M, van Eeden FJ, Furutani-Seiki M, Granato M, Hammerschmidt M, Heisenberg CP, Jiang YJ, Kane DA, Kelsh RN, Mullins MC, NussleinVolhard C. Mutations affecting the cardiovascular system and other internal organs in zebrafish. Development. 1996; 123:293-302. [PubMed: 9007249]

Davuluri G, Gong W, Yusuff S, Lorent K, Muthumani M, Dolan AC, Pack M. Mutation of the zebrafish nucleoporin elys sensitizes tissue progenitors to replication stress. PLoS Genet. 2008; 4:e1000240. [PubMed: 18974873]

Davuluri G, Seiler C, Abrams J, Soriano AJ, Pack M. Differential effects of thin and thick filament disruption on zebrafish smooth muscle regulatory proteins. Neurogastroenterol Motil. 2010; 22:1100-e285. [PubMed: 20591105]

De Calisto J, Araya C, Marchant L, Riaz CF, Mayor R. Essential role of non-canonical Wnt signalling in neural crest migration. Development. 2005; 132:2587-97. [PubMed: 15857909] 
de Jong-Curtain TA, Parslow AC, Trotter AJ, Hall NE, Verkade H, Crowhurst MO, Layton JE, Shepherd IT, Nixon SJ, Parton RG, Zon LI, Stainier DY, Lieschke GJ, Heath JK. Abnormal Nuclear Pore Formation Triggers Apoptosis in the Intestinal Epithelium of elys-Deficient Zebrafish. Gastroenterology. 2008; 136:902-911. [PubMed: 19073184]

Delalande JM, Guyote ME, Smith CM, Shepherd IT. Zebrafish sip1a and sip1b are essential for normal axial and neural patterning. Dev Dyn. 2008; 237:1060-9. [PubMed: 18351671]

Druckenbrod NR, Epstein ML. The pattern of neural crest advance in the cecum and colon. Dev Biol. 2005; 287:125-33. [PubMed: 16197939]

Dutton JR, Antonellis A, Carney TJ, Rodrigues FS, Pavan WJ, Ward A, Kelsh RN. An evolutionarily conserved intronic region controls the spatiotemporal expression of the transcription factor Sox 10 . BMC Dev Biol. 2008; 8:105. [PubMed: 18950534]

Dutton KA, Pauliny A, Lopes SS, Elworthy S, Carney TJ, Rauch J, Geisler R, Haffter P, Kelsh RN. Zebrafish colourless encodes sox 10 and specifies non-ectomesenchymal neural crest fates. Development. 2001; 128:4113-25. [PubMed: 11684650]

Elworthy S, Pinto JP, Pettifer A, Cancela ML, Kelsh RN. Phox2b function in the enteric nervous system is conserved in zebrafish and is sox10-dependent. Mech Dev. 2005; 122:659-69. [PubMed: 15817223]

Field H, Kelley K, Martell L, Goldstein A, Serluca F. Analysis of Gastrointestinal Physiology Using a Novel Intestinal Transit Assay in Zebrafish. Neurogasteroenterology \& Motility. 2008

Fisher S, Grice EA, Vinton RM, Bessling SL, McCallion AS. Conservation of RET regulatory function from human to zebrafish without sequence similarity. Science. 2006; 312:276-9. [PubMed: 16556802]

Fu M, Lui VC, Sham MH, Pachnis V, Tam PK. Sonic hedgehog regulates the proliferation, differentiation, and migration of enteric neural crest cells in gut. J Cell Biol. 2004; 166:673-84. [PubMed: 15337776]

Furness, JB. The Enteric Nervous System. Blackwell; Oxford, UK: 2006.

Gershon, MD. The second brain. HarperCollins; New York: 1998.

Gershon MD. Developmental determinants of the independence and complexity of the enteric nervous system. Trends Neurosci. 2010

Gershon MD, Tack J. The serotonin signaling system: from basic understanding to drug development for functional GI disorders. Gastroenterology. 2007; 132:397-414. [PubMed: 17241888]

Gill SR, Pop M, Deboy RT, Eckburg PB, Turnbaugh PJ, Samuel BS, Gordon JI, Relman DA, FraserLiggett CM, Nelson KE. Metagenomic analysis of the human distal gut microbiome. Science. 2006; 312:1355-9. [PubMed: 16741115]

Grunwald DJ, Eisen JS. Headwaters of the zebrafish -- emergence of a new model vertebrate. Nat Rev Genet. 2002; 3:717-24. [PubMed: 12209146]

Heanue TA, Pachnis V. Ret isoform function and marker gene expression in the enteric nervous system is conserved across diverse vertebrate species. Mech Dev. 2008; 125:687-99. [PubMed: 18565740]

Holmberg A, Olsson C, Hennig GW. TTX-sensitive and TTX-insensitive control of spontaneous gut motility in the developing zebrafish (Danio rerio) larvae. J Exp Biol. 2007; 210:1084-91. [PubMed: 17337720]

Holmberg A, Olsson C, Holmgren S. The effects of endogenous and exogenous nitric oxide on gut motility in zebrafish Danio rerio embryos and larvae. J Exp Biol. 2006; 209:2472-9. [PubMed: 16788030]

Holmberg A, Schwerte T, Pelster B, Holmgren S. Ontogeny of the gut motility control system in zebrafish Danio rerio embryos and larvae. J Exp Biol. 2004; 207:4085-94. [PubMed: 15498954]

Holmberg A, Schwerte T, Fritsche R, Pelster B, Holmgren S. Ontogeny of intestinal motility in correlation to neuronal development in zebrafish embryos and larvae. Journal of Fish Biology. $2003 ; 63: 318-331$.

Huizinga JD, Berezin I, Sircar K, Hewlett B, Donnelly G, Bercik P, Ross C, Algoufi T, Fitzgerald P, Der T, Riddell RH, Collins SM, Jacobson K. Development of interstitial cells of Cajal in a fullterm infant without an enteric nervous system. Gastroenterology. 2001; 120:561-7. [PubMed: 11159897] 
Ito M, Okano HJ, Darnell RB, Roeder RG. The TRAP100 component of the TRAP/Mediator complex is essential in broad transcriptional events and development. EMBO J. 2002; 21:3464-75. [PubMed: 12093747]

Kanther M, Rawls JF. Host-microbe interactions in the developing zebrafish. Curr Opin Immunol. 2010; 22:10-9. [PubMed: 20153622]

Kelsh RN, Eisen JS. The zebrafish colourless gene regulates development of non-ectomesenchymal neural crest derivatives. Development. 2000; 127:515-25. [PubMed: 10631172]

Kuhlman J, Eisen JS. Genetic screen for mutations affecting development and function of the enteric nervous system. Dev Dyn. 2007; 236:118-27. [PubMed: 17131406]

Landman KA, Simpson MJ, Newgreen DF. Mathematical and experimental insights into the development of the enteric nervous system and Hirschsprung's disease. Dev Growth Differ. 2007; 49:277-86. [PubMed: 17501905]

Le Douarin, N.; Kalcheim, C. The neural crest. Cambridge University Press; Cambridge: 1999.

Lecoin L, Gabella G, Le Douarin N. Origin of the c-kit-positive interstitial cells in the avian bowel. Development. 1996; 122:725-33. [PubMed: 8631250]

Lomax AE, Fernandez E, Sharkey KA. Plasticity of the enteric nervous system during intestinal inflammation. Neurogastroenterol Motil. 2005; 17:4-15. [PubMed: 15670258]

Lucini C, Maruccio L, Tafuri S, Bevaqua M, Staiano N, Castaldo L. GDNF family ligand immunoreactivity in the gut of teleostean fish. Anat Embryol (Berl). 2005; 210:265-74. [PubMed: 16193278]

Lucini C, Maruccio L, Tafuri S, Staiano N, Castaldo L. Artemin-like immunoreactivity in the zebrafish, Danio rerio. Anat Embryol (Berl). 2004; 208:403-10. [PubMed: 15309630]

Lyons DA, Naylor SG, Mercurio S, Dominguez C, Talbot WS. KBP is essential for axonal structure, outgrowth and maintenance in zebrafish, providing insight into the cellular basis of GoldbergShprintzen syndrome. Development. 2008; 135:599-608. [PubMed: 18192286]

Marcos-Gutierrez CV, Wilson SW, Holder N, Pachnis V. The zebrafish homologue of the ret receptor and its pattern of expression during embryogenesis. Oncogene. 1997; 14:879-89. [PubMed: 9050987]

McGaughey DM, Vinton RM, Huynh J, Al-Saif A, Beer MA, McCallion AS. Metrics of sequence constraint overlook regulatory sequences in an exhaustive analysis at phox2b. Genome Res. 2008; 18:252-60. [PubMed: 18071029]

Minchin JE, Hughes SM. Sequential actions of Pax3 and Pax7 drive xanthophore development in zebrafish neural crest. Dev Biol. 2008; 317:508-22. [PubMed: 18417109]

Montero-Balaguer M, Lang MR, Sachdev SW, Knappmeyer C, Stewart RA, De La Guardia A, Hatzopoulos AK, Knapik EW. The mother superior mutation ablates foxd3 activity in neural crest progenitor cells and depletes neural crest derivatives in zebrafish. Dev Dyn. 2006; 235:3199-212. [PubMed: 17013879]

Muncan V, Faro A, Haramis AP, Hurlstone AF, Wienholds E, van Es J, Korving J, Begthel H, Zivkovic D, Clevers H. T-cell factor 4 (Tcf712) maintains proliferative compartments in zebrafish intestine. EMBO Rep. 2007; 8:966-73. [PubMed: 17823612]

Nagy N, Mwizerwa O, Yaniv K, Carmel L, Pieretti-Vanmarcke R, Weinstein BM, Goldstein AM. Endothelial cells promote migration and proliferation of enteric neural crest cells via beta1 integrin signaling. Dev Biol. 2009; 330:263-72. [PubMed: 19345201]

Ng AN, de Jong-Curtain TA, Mawdsley DJ, White SJ, Shin J, Appel B, Dong PD, Stainier DY, Heath JK. Formation of the digestive system in zebrafish: III. Intestinal epithelium morphogenesis. Dev Biol. 2005; 286:114-35. [PubMed: 16125164]

Njagi J, Ball M, Best M, Wallace KN, Andreescu S. Electrochemical quantification of serotonin in the live embryonic zebrafish intestine. Anal Chem. 2010; 82:1822-30. [PubMed: 20148518]

Olden T, Akhtar T, Beckman SA, Wallace KN. Differentiation of the zebrafish enteric nervous system and intestinal smooth muscle. Genesis. 2008; 46:484-98. [PubMed: 18781646]

Olsson C, Holmberg A, Holmgren S. Development of enteric and vagal innervation of the zebrafish (Danio rerio) gut. J Comp Neurol. 2008; 508:756-70. [PubMed: 18393294] 
Parichy DM, Mellgren EM, Rawls JF, Lopes SS, Kelsh RN, Johnson SL. Mutational analysis of endothelin receptor b1 (rose) during neural crest and pigment pattern development in the zebrafish Danio rerio. Dev Biol. 2000; 227:294-306. [PubMed: 11071756]

Pietsch J, Delalande JM, Jakaitis B, Stensby JD, Dohle S, Talbot WS, Raible DW, Shepherd IT. lessen encodes a zebrafish trap100 required for enteric nervous system development. Development. 2006; 133:395-406. [PubMed: 16396911]

Plaster N, Sonntag C, Busse CE, Hammerschmidt M. p53 deficiency rescues apoptosis and differentiation of multiple cell types in zebrafish flathead mutants deficient for zygotic DNA polymerase delta1. Cell Death Differ. 2006; 13:223-35. [PubMed: 16096653]

Poon KL, Richardson M, Lam CS, Khoo HE, Korzh V. Expression pattern of neuronal nitric oxide synthase in embryonic zebrafish. Gene Expr Patterns. 2003; 3:463-6. [PubMed: 12915313]

Reichenbach B, Delalande JM, Kolmogorova E, Prier A, Nguyen T, Smith CM, Holzschuh J, Shepherd IT. Endoderm-derived Sonic hedgehog and mesoderm Hand2 expression are required for enteric nervous system development in zebrafish. Dev Biol. 2008; 318:52-64. [PubMed: 18436202]

Rich A, Leddon SA, Hess SL, Gibbons SJ, Miller S, Xu X, Farrugia G. Kit-like immunoreactivity in the zebrafish gastrointestinal tract reveals putative ICC. Dev Dyn. 2007; 236:903-11. [PubMed: 17295318]

Roberts RR, Ellis M, Gwynne RM, Bergner AJ, Lewis MD, Beckett EA, Bornstein JC, Young HM. The first intestinal motility patterns in fetal mice are not mediated by neurons or interstitial cells of Cajal. J Physiol. 2010; 588:1153-69. [PubMed: 20142273]

Salonen A, de Vos WM, Palva A. Gastrointestinal Microbiota in Irritable Bowel Syndrome: Present State and Perspectives. Microbiology. 2010

Sauka-Spengler T, Bronner-Fraser M. A gene regulatory network orchestrates neural crest formation. Nat Rev Mol Cell Biol. 2008; 9:557-68. [PubMed: 18523435]

Schilling TF, Piotrowski T, Grandel H, Brand M, Heisenberg CP, Jiang YJ, Beuchle D, Hammerschmidt M, Kane DA, Mullins MC, van Eeden FJ, Kelsh RN, Furutani-Seiki M, Granato M, Haffter P, Odenthal J, Warga RM, Trowe T, Nusslein-Volhard C. Jaw and branchial arch mutants in zebrafish I: branchial arches. Development. 1996; 123:329-44. [PubMed: 9007253]

Seiler C, Abrams J, Pack M. Characterization of zebrafish intestinal smooth muscle development using a novel sm22alpha-b promoter. Dev Dyn.

Shepherd IT, Beattie CE, Raible DW. Functional analysis of zebrafish GDNF. Dev Biol. 2001; 231:420-35. [PubMed: 11237470]

Shepherd IT, Pietsch J, Elworthy S, Kelsh RN, Raible DW. Roles for GFRalpha1 receptors in zebrafish enteric nervous system development. Development. 2004; 131:241-9. [PubMed: 14660438]

Southard Smith EM, Kos L, Pavan WJ. Sox 10 mutation disrupts neural crest development in Dom Hirschsprung mouse model. Nat Genet. 1998; 18:60-4. [PubMed: 9425902]

Stewart RA, Arduini BL, Berghmans S, George RE, Kanki JP, Henion PD, Look AT. Zebrafish foxd3 is selectively required for neural crest specification, migration and survival. Dev Biol. 2006; 292:174-88. [PubMed: 16499899]

Tapadia MD, Cordero DR, Helms JA. It's all in your head: new insights into craniofacial development and deformation. J Anat. 2005; 207:461-77. [PubMed: 16313388]

Tobin JL, Di Franco M, Eichers E, May-Simera H, Garcia M, Yan J, Quinlan R, Justice MJ, Hennekam RC, Briscoe J, Tada M, Mayor R, Burns AJ, Lupski JR, Hammond P, Beales PL. Inhibition of neural crest migration underlies craniofacial dysmorphology and Hirschsprung's disease in Bardet-Biedl syndrome. Proc Natl Acad Sci U S A. 2008; 105:6714-9. [PubMed: 18443298]

Uyttebroek L, Shepherd I, Harrisson F, Hubens G, Blust R, Timmermans JP, Van Nassauw L. Neurochemical Coding of Enteric Neurons in Adult and Embryonic Zebrafish (Danio rerio). J Comp Neurol. 2010; 518:4419-38. [PubMed: 20853514]

Wallace KN, Akhter S, Smith EM, Lorent K, Pack M. Intestinal growth and differentiation in zebrafish. Mech Dev. 2005; 122:157-73. [PubMed: 15652704] 
Wallace KN, Pack M. Unique and conserved aspects of gut development in zebrafish. Dev Biol. 2003; 255:12-29. [PubMed: 12618131]

Ward SM, Ordog T, Bayguinov JR, Horowitz B, Epperson A, Shen L, Westphal H, Sanders KM. Development of interstitial cells of Cajal and pacemaking in mice lacking enteric nerves. Gastroenterology. 1999; 117:584-94. [PubMed: 10464134]

Yee NS, Gong W, Huang Y, Lorent K, Dolan AC, Maraia RJ, Pack M. Mutation of RNA Pol III subunit rpc2/polr3b Leads to Deficiency of Subunit Rpc11 and disrupts zebrafish digestive development. PLoS Biol. 2007; 5:e312. [PubMed: 18044988]

Young HM. Embryological origin of interstitial cells of Cajal. Microsc Res Tech. 1999; 47:303-8. [PubMed: 10602289]

Young HM, Bergner AJ, Anderson RB, Enomoto H, Milbrandt J, Newgreen DF, Whitington PM. Dynamics of neural crest-derived cell migration in the embryonic mouse gut. Dev Biol. 2004; 270:455-73. [PubMed: 15183726] 

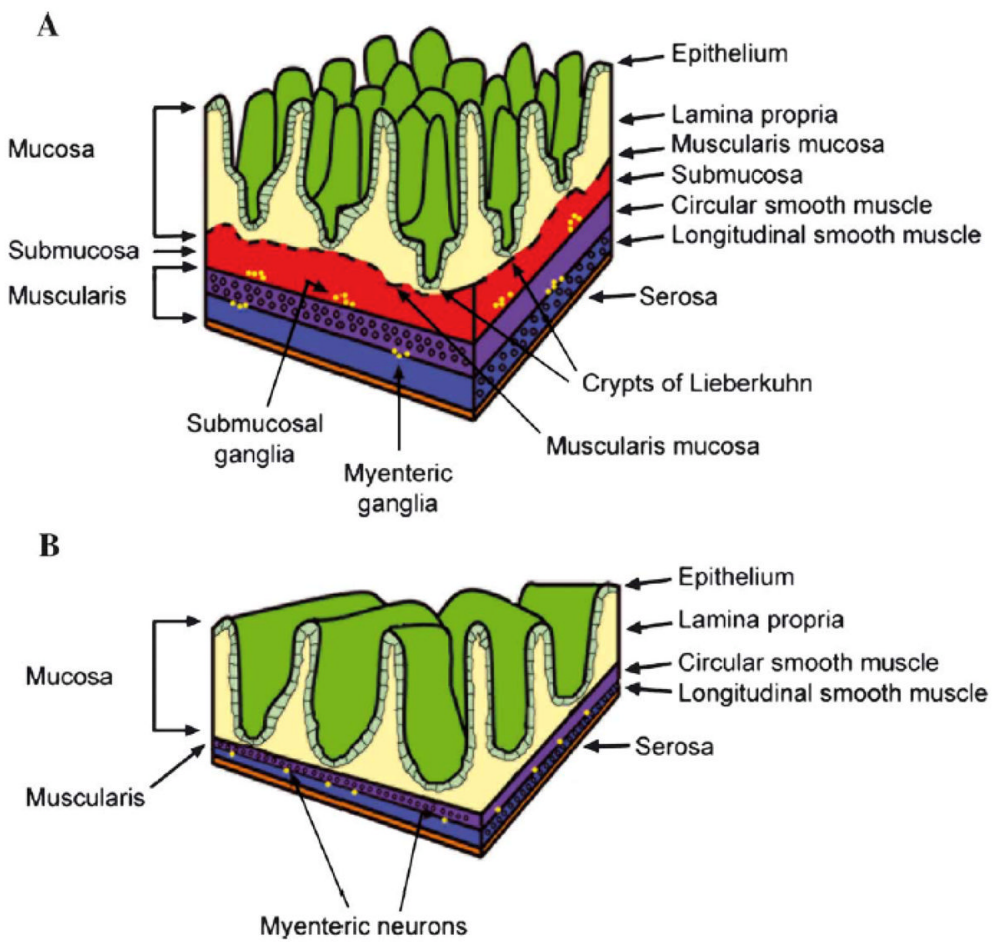

Figure 1.

Comparison of mammalian (A) and zebrafish (B) intestinal architecture. Reprinted from Wallace et al 2005 with permission from Elsevier. 

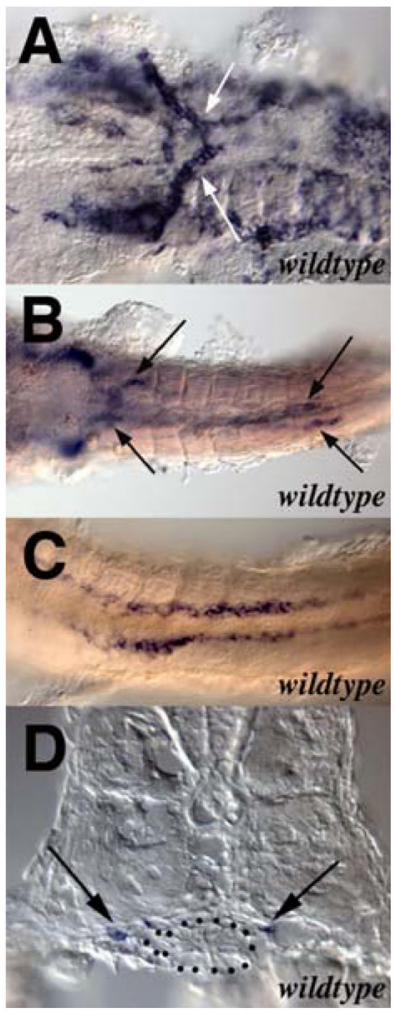

Figure 2.

Migration of neural crest cells into the zebrafish gut. Modified from Shepherd et al 2004 with permission of The Company of Biologists. 

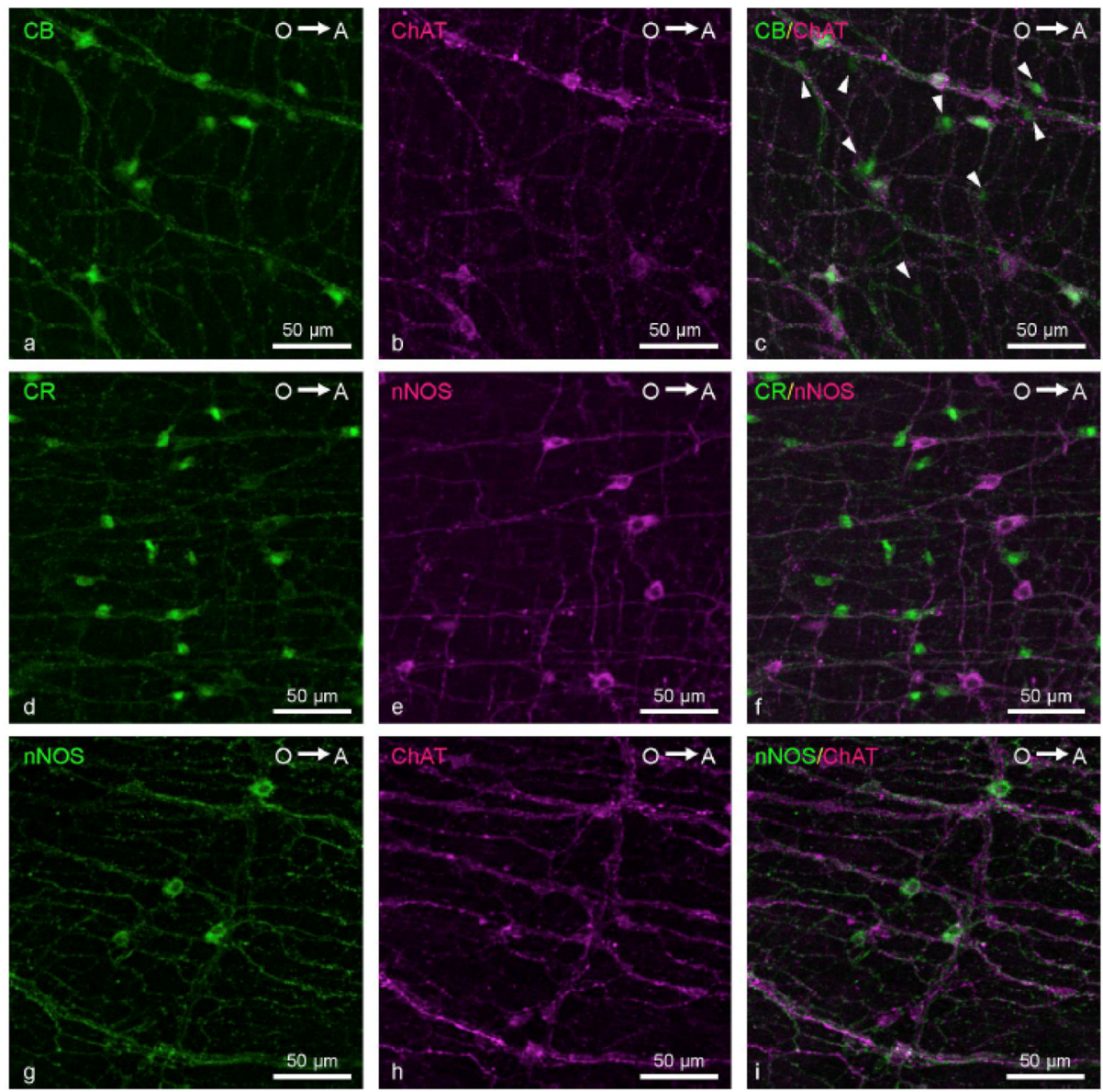

Figure 3.

Coexpression of neurotransmitters in adult zebrafish ENS neurons. From Uyttebroek et al. 2010 with permission from John Wiley and Sons Inc. 

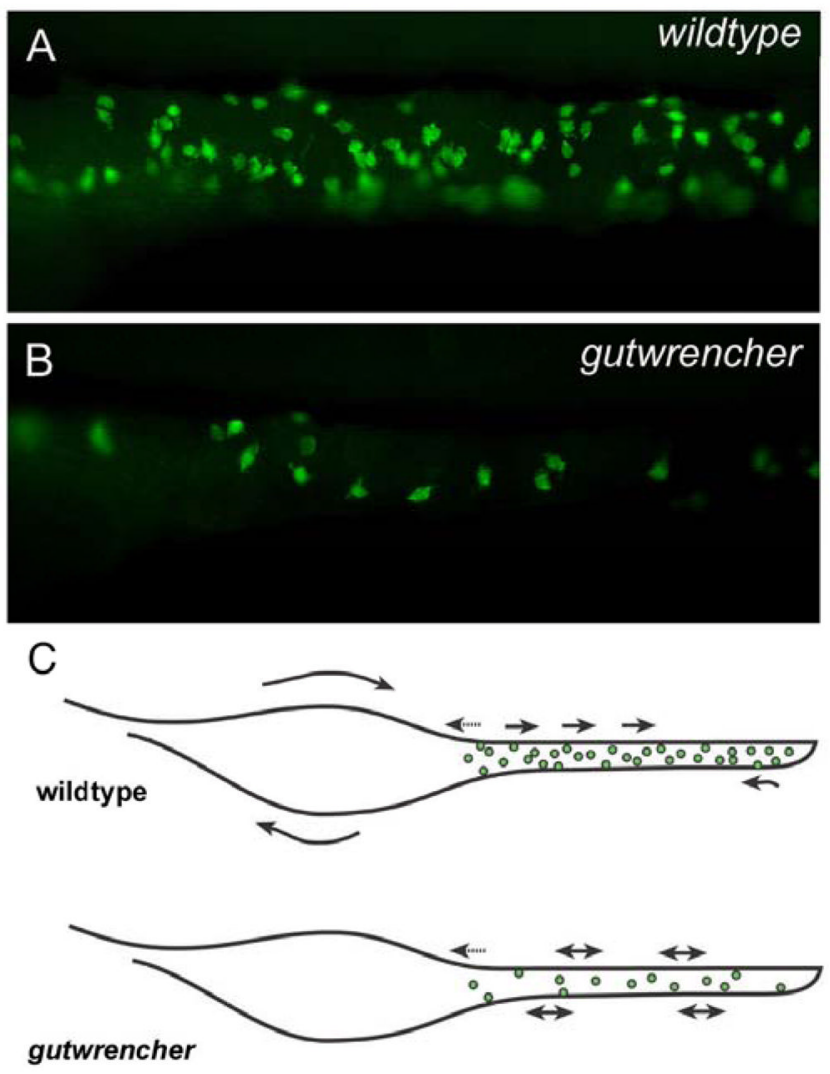

Figure 4.

gutwrencher mutants have fewer ENS neurons and less regular gut motility than wildtypes. Modified from Kuhlman et al 2007 with permission of John Wiley and Sons Inc. 